\title{
SUITABILITY AND COST-WISE COMPARATIVE ANALYSIS OF RIGID AND FLEXIBLE PAVEMENTS: A REVIEW
}

\author{
Dagimwork Asele Manuka \\ Department of Civil Engineering \\ Wolaita Sodo University, Wolaita Sodo, Ethiopia
}

\begin{abstract}
Flexible pavements are widely used despite some doubts regarding their economics under different conditions. Two most important parameters that govern the pavement design are soil sub-grade and traffic loading. ERA manual for the design of flexible pavements use soil subgrade strength in terms of California Bearing Ratio (CBR) and traffic loading in terms of million standard axles (ESA). For the design of rigid pavements uses ESA in millions it doesn't depend on the soil subgrade level. To compare the cost of two types of pavements, it is necessary to ensure that they are designed for the design parameters but the design period of rigid pavement is twice the design period of flexible pavement, so this paper tries to cover design criteria and procedure for design of rigid pavement and compares the flexible and rigid pavements in various parameters and conditions and forward engineering ideas.
\end{abstract}

Keywords- Parameters, ESA, Flexible pavement, rigid pavement and Design Criteria.

\section{INTRODUCTION}

The development of a country depends on the assembly of various places within countries with adequate road network. Roads are the main channel for the transport of goods and passengers. The benefits of investment in the road sector are indirect, long-term and not immediately visible. Roads are essential asset for any nation. However, the creation of these assets alone is not enough they must be carefully planned, as pavement that is not well-designed and constructed quickly collapse [15].

The performance of pavements depends upon the quality of sub grades and sub bases. A stable sub grade and properly draining sub base help produces a long-lasting pavement. A high level of spatial uniformity of a sub grade and sub base in terms of key engineering parameters such as shear strength, stiffness, volumetric stability, and permeability is vital for the effective performance of the pavement system. A number of environmental variables such as temperature and moisture affect these geotechnical characteristics, both in short and longterm.

\author{
Mengistu Mena Kuleno \\ Department of Civil Engineering \\ Wolaita Sodo University, Wolaita Sodo, Ethiopia
}

[10] Reported that generally there are two type of pavement structure: flexible and rigid pavement. Flexible pavements are intended to limit the stress created at the sub grade level by the traffic traveling on the pavement surface, so that the sub grade is not subject to significant deformations. In effect, the concentrated loads of the vehicle wheels are spread over a sufficiently larger area at sub grade level. At the same time, the pavement materials themselves should not deteriorate to such an extent as to affect the riding quality and functionality of the pavement. These goals must be achieved throughout a specific design period.

Rigid pavements (concrete pavements), as the name implies, are rigid and considerably stronger in compression than in tension. One of the main characteristics of rigid pavements is that a relatively thin pavement slab distributes the load over a wider area due to its high rigidity. Localized low strength roadbed material can be overcome due to this wider distribution area. In concrete pavements, the strength of the pavement is contributed mainly by the concrete slab, unlike flexible pavements where successive layers of the pavement contribute cumulatively.

There are two main types of failure, functional and structural, associated with pavement deterioration. Functional failure is that wherein the pavement is unable to carry traffic without causing discomfort to the road users. This failure depends primarily upon the degree of surface roughness. Structural failure, on the other hand, indicates a breakdown of one or more component making it incapable of sustaining the loads imposed upon its surface. In flexible pavements, this failure may result from bituminous surface fatigue, consolidation, settlement, and shear developing in the sub grade or inadequate performance of the subs, road base, and surface, as a result of in adequate pavement thickness.

Structural design of flexible and rigid pavement is crucial criteria for comparing these two types of pavements. This thesis intends to investigate the possible differences between the two types of pavements and gives detailed comparative results about these pavement types.

\subsection{Statement of Problem}

In Ethiopia roadway construction was increasing enormously. Almost all part of the country, roads are constructed using 


\section{International Journal of Engineering Applied Sciences and Technology, 2019 \\ Vol. 4, Issue 6, ISSN No. 2455-2143, Pages 20-28 \\ Published Online October 2019 in IJEAST (http://www.ijeast.com)}

flexible pavement this is not due to inadequacy of rigid pavement but it is because of lack of tradition (skill) and experience. In developing countries like Ethiopia early age deterioration of flexible pavement is becoming common problems. Fast growth in vehicle, weather condition and variations, materials usages during construction are among the major problems behind early age flexible pavement deterioration.

This pavement deterioration is becoming a source of hazards in road way environment. When roads are associated with number of hazards, the driver of the vehicles will have lot of risk on the roads. The risk factor is very high as the number of hazards are increasing on the roads. A risk factor is a negative outcome and indicates the probability of occurring an accident. The maintenance cost, rehabilitation cost and the costs of daily accidents occurring on road way environment due to bad surface highly affects the country economy and development. The main point of this study is that to decide which pavement type is appropriate for our country by studying cost-wise comparison and suitability by considering basic design and environmental impacts.

\subsection{Main Objective}

The main objective of this study is to compare the pavement types based on engineering parameters, and introduce information to choose suitable pavement into country if it becomes appropriate after this study.

\subsection{Specific Objectives}

The specific objectives of the study are:

- To study the behavior of types of pavement.

- Comparing rigid and flexible pavements accordingly with their initial cost, maintenance cost, safety and others.

- Providing basic design criteria and procedure for proper design of rigid pavement.

\section{PAVEMENT STRUCTURE}

The road pavement is the actual surface on which the vehicles will travel. Its purpose is to fold, to provide friction for the vehicles and to transfer normal stresses to the underlying soils. In broad terms, the two main pavement types can be described briefly as:

\subsection{Rigid pavement}

According to [13] rigid pavements have sufficient flexural strength to transmit wheel load stresses to wider area Compared to flexible pavement, rigid pavements are placed either directly on the prepared sub-grade or on a single layer of granular or stabilized material. Localized low strength roadbed material can be overcome due to this wider distribution area. In concrete pavements, the strength of the pavement is contributed mainly by the concrete slab.
Rigid pavements have often been considered only for heavily trafficked roads because of their initial high cost and their excellent traffic carrying capacity. As a result, the major portion of the paved road network in most countries consists of flexible pavements. However, several countries have adopted rigid pavements more widely. This is because they last a long time and their maintenance demands are low so that, in whole life cost terms, they can provide good value for money. Naturally this depends on the relative costs of the materials, but rigid pavements have a role to play across the entire traffic spectrum and, on low volume roads, can be used to advantage in difficult situations where other types of road pavement may not be durable and sustainable.

Rigid pavements (also called concrete pavements) usually comprise two or three layers; a capping layer if the sub grade is weak, a sub-base layer and a strong, stiff concrete layer. The specifications for the capping layer and sub-base and methods of determining the strength of the sub grade for design purposes are essentially the same as for flexible pavements. As the name 'rigid' implies, the deflections under a loaded wheel are very small compared with the deflections observed in flexible pavements and the stresses within the underlying subbase and sub grade are also comparatively small. Rigid pavements therefore deteriorate through quite different mechanisms from those that affect flexible pavements.

Concrete pavement has Advantages over bituminous pavement. Few of them are it has more useful life, low cost of maintenance, provide good visibility for night driving, it requires lesser amount of aggregates and no flame thereby more environmentally friendly, can be constructed under unfavorable soil condition, practically unaffected by weather and temperature [1].

Concrete pavements have not been used extensively in most tropical countries including Ethiopia. This is mainly due to a lack of tradition and experience in their design and construction. However, several tropical countries have invested heavily and successfully in rigid pavements (e.g. Philippines and Chile) and their use is widespread in Europe and the USA. There appears to be no technical reason why more use should not be made of them in Ethiopia.

Depending on the level of reinforcement [13], the rigid pavements can be categorized into three basic types:

- Jointed unreinforced concrete pavements (JUCP)

- Jointed reinforced concrete pavements (JRCP)

- Continuously reinforced concrete pavements (CRCP)

- $\quad$ Pre-stressed concrete pavements (PSCP)

\section{Jointed Unreinforced Concrete Pavement}

In jointed unreinforced concrete pavements (JUCP), the pavement consists in a succession of cast in place unreinforced concrete slabs separated by joints to prevent expansion from developing stresses and to control cracks. The slabs are linked together by tie bars or dowels to transmit the vertical stresses in Jointed Unreinforced Concrete Pavements (JUCP) the 


\section{International Journal of Engineering Applied Sciences and Technology, 2019 \\ Vol. 4, Issue 6, ISSN No. 2455-2143, Pages 20-28 \\ Published Online October 2019 in IJEAST (http://www.ijeast.com)}

pavement consists of unreinforced concrete slabs cast in place and divided into bays of predetermined dimensions by the construction of joints. The dimensions of the bays are made sufficiently short to ensure that they do not crack through shrinkage during the concrete curing process. In the longitudinal direction the bays are usually linked together by dowels to prevent vertical movement and to help maintain aggregate interlock across the transverse joints. The bays are also connected to parallel slabs by tie bars, the main function of which is to prevent horizontal movement (i.e. the opening of warping joints).

\section{Jointed Reinforced Concrete Pavement}

In Jointed reinforced concrete pavements (JRCP) the pavement consists in a succession of cast in place reinforced concrete slabs separated by joints to prevent expansion from developing stresses and to control cracks. The slabs are linked together by tie bars or dowels to transmit the vertical stresses. JRCP are used where a probability exists for transverse cracking during pavement life due to such factors as soil movement and/or temperature/moisture change stresses. The longitudinal reinforcement is the main reinforcement. A transverse reinforcement though not absolutely necessary in most cases is usually added to facilitate the placing of longitudinal bars.

In Jointed Reinforced Concrete Pavements (JRCP) the pavement consists of cast in place concrete slabs containing steel reinforcement and divided into bays separated by joints. The reinforcement is to prevent cracks from opening and this allows much longer bays to be used than for JUCP. The bays are linked together by dowels and tie bars as in JUCP. Although longitudinal reinforcement is the main reinforcement, transverse reinforcement is also used in most cases to facilitate the placing of longitudinal bars.

\section{Continuously Reinforced Concrete Pavement}

Continuously reinforced concrete pavements (CRCP) are used for rather trafficked roads where a good level of comfort is expected. The principal reinforcement, in the form of prefabricated mesh or reinforcing bars installed at mid-depth of the slab, is again the longitudinal steel which is essentially continuous throughout the length of the pavement. This longitudinal reinforcement is used to control cracks which form in the pavement due to volume change in the concrete. Continuously Reinforced Concrete Pavements (CRCP) is made of cast in place reinforced concrete slabs without joints. The expansion and contraction movements are prevented by a high level of sub-base restraint. The frequent transverse cracks are held tightly closed by a large amount of continuous high tensile steel longitudinal reinforcement.

\subsubsection{Construction of Concrete road surfacing}

[14] Stated that there are a number of key issues that must be addressed in order to properly construct a concrete pavement. These include the positioning of the reinforcement in the concrete, the correct forming of both joints and slabs and the chosen method of construction. Concrete paving is a dynamic and vigorous process, so it is imperative that the steel reinforcement is kept firmly in place throughout. Dowel bars used in expansion and contraction joints are usually positioned on metal cradles so that they will not move from their required position while the concrete is being placed and compacted. Tie-bars in warping joints are also normally part of a rigid construction that allows them to be firmly secured to the supporting subbase, while those in construction joints can be inserted into the side of the pavement slab and re compacted.

Tie bars are deformed rebar or connectors used for holding faces of rigid slabs in contact to maintain aggregate interlock. Tie bars are not load transferring device. For instance, tie bars are used in longitudinal joints in concrete pavement [14]. Dowel bars are smooth round bars which mainly serve as load transfer device across concrete joints. They are placed across transverse joints of concrete pavement to allow movement to take place. Where movement is purposely designed for longitudinal joints, dowel bars can be adopted [14].

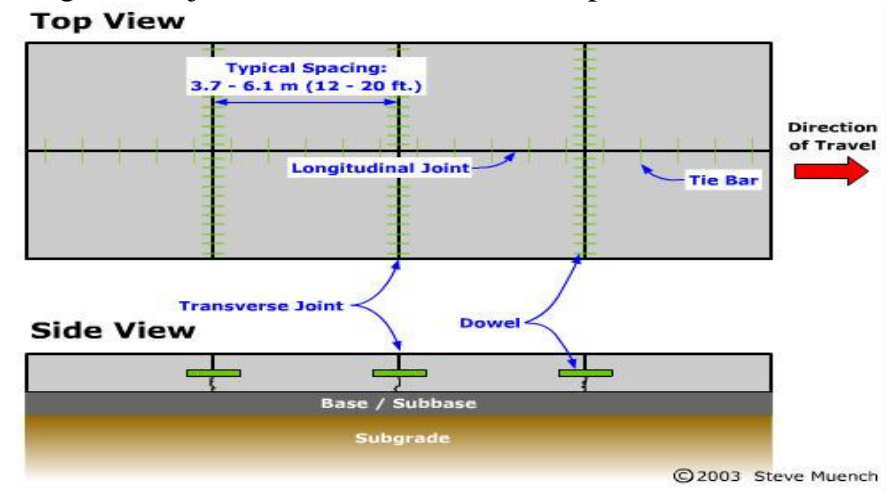

Figure-1: Typical section of rigid pavement

\subsection{Flexible pavement}

Flexible pavement is composed of a bituminous material surface course and underlying base and subbase courses. The bituminous material is more often asphalt whose viscous nature allows significant plastic deformation. Most asphalt surfaces are built on a gravel base, although some 'full depth' asphalt surfaces are built directly on the subgrade. Depending on the temperature at which it is applied, asphalt is categorized as hot mix asphalt (HMA), warm mix asphalt, or cold mix asphalt. Flexible Pavement is so named as the pavement surface reflects the total deflection of all subsequent layers due to the traffic load acting upon it. The flexible pavement design is based on the load distributing characteristics of a layered system [12].

Flexible pavements comprise more than 90 percent of our paved roads. There are many different types of flexible pavements. Hot Mix Asphalt (HMA) mix types are more commonly used. Other flexible pavements such as bituminous surface treatments (BSTs) are considered by most agencies to be a form of maintenance and are thus covered under maintenance and rehabilitation. HMA mix types differ from each other mainly in maximum aggregate size, aggregate 


\section{International Journal of Engineering Applied Sciences and Technology, 2019 \\ Vol. 4, Issue 6, ISSN No. 2455-2143, Pages 20-28 \\ Published Online October 2019 in IJEAST (http://www.ijeast.com)}

gradation and asphalt binder content or type. Guides are• available on dense-graded HMA in most flexible pavement• sections because it is the most common pavement material. (HAPI, 2002) components make it incapable of sustaining the loads imposed upon its surface. This failure may result from bituminous surface fatigue, consolidation, settlement, and shear developing in the sub grade or inadequate performance of the subs, road base, and surface, as a result of inadequate pavement thickness.

\section{EVALUATION OF RIGID AND FLEXIBLE PAVEMENT}

According to [4] released a position paper that concluded that pavement type selection should be a road user-oriented process, not an industry-oriented process. It states that the system used to select pavement type should be objective, defensible, understandable, and based on historical records, primarily driven by economics and periodically reviewed. APA supports the use of life-cycle cost analysis in the decisionmaking process and recommends the methodology developed by the Federal Highway Administration (FHWA) in Demonstration Project 115. The Net Present Value (NPV) is used for the purpose of comparing alternatives. Initial costs, maintenance costs, and salvage value are recommended for consideration in the life-cycle cost analysis. APA recommends a 40-year analysis period when comparing asphalt with concrete pavements. APA states that asphalt pavements possess many advantages when compared with concrete pavements including low initial cost, low maintenance costs, flexibility and speed of construction, the ability to handle heavy loads, a long life, and complete recyclability.

Newcomb, in an article published in Centerline in 2004 with news from the Asphalt Pavement Association of Oregon, stated that primary factors affecting pavement type selection Include traffic, soil characteristics, weather, and construction considerations. Newcomb stated that the pavement type selection process must be a rational process, based not only on financial Costs but on facts concerning performance, cost of the pavement structure, speed and timing in construction, safety, and realistic maintenance and rehabilitation schedules. In his opinion, asphalt pavements offer specific advantages when compared with concrete pavements.

[5]. American Concrete Pavement Association states that concrete pavements are a better choice than asphalt pavements because they have advantages in several areas including safety, durability, smoothness, versatility, and value. On safety, it provides better visibility, reduced wet spray since concrete never ruts, and provides the best traction grip. On durability, concrete hardens over time, and outlasts flexible materials since their average life span is 30 years. On smoothness, concrete stays smoother longer, creating safer, comfortable transportation surfaces and saving fuel. On versatility, concrete pavements can be

- -Designed to last from 10 to 50 years,
-Used to rehabilitate old asphalt pavement using white topping, -Used to rehabilitate a worn concrete pavement.

On value, concrete pavements provide the best long-term value due to their longer life, they are easy to repair, and they can be built and opened to traffic in less than 12 hours. In 2002, ACPA published a guide for comparing alternate pavement designs using LCCA. The guide describes the LCCA process factors that influence the results including agency costs (initial cost, maintenance and rehabilitation costs, salvage value), user costs (delay of-use costs, roadway deterioration costs, and accident crash cost), discount rate, selection of rehabilitation activities, use of comparable sections, and length of the analysis period. Present worth (PW) and the equivalent uniform annual cost (EUAC) are mentioned as economic indicators used to express LCCA results. APA recommends EUAC because all costs are expressed in terms of an annual cost over the analysis period. The guide also presents a brief summary of life-cycle cost and performance studies conducted with historical data in Michigan, Minnesota, Iowa, Florida, Tennessee, South Dakota, Utah, and Georgia. According to these studies, concrete sections lasted between 1.6 and 2.6 times longer than the asphalt sections and were from 14 percent to 250 percent more effective than the asphalt pavements.

There is one major difference between concrete and asphalt road surfaces. Concrete pavement is a rigid structure and asphalt is a flexible structure. Historically, pavements have been divided into two broad categories, rigid and flexible. These classical definitions, in some cases, are an oversimplification. However, the terms rigid and flexible provide a good description of how the pavements react to traffic loads and the environment.

The flexible pavement is an asphalt pavement. It generally consists of a surface of asphalt built over a base course and sub base course. Base and sub base courses are usually gravel or stone. These layers rest upon a compacted sub grade (compacted soil). In contrast, rigid highway pavements are made up of Portland cement concrete and have only a base course between the pavement and sub grade.

Rigid pavements area concrete pavement usually consists of a sub-base and a concrete slab but a capping layer is also used if required. When the subgrade is weak, the required thickness of material of sub-base quality required to protect the sub grade and to provide sufficient [9].

Support for the concrete slab is substantial and it is usually more economical to provide a capping layer to perform part of the task. Any erosion of the sub-base layer under the concrete slab caused by the pumping action as traffic uses the road reduces the support to the concrete slab. This increases the tensile strains in the concrete itself and therefore the risk of cracking. In circumstances where this is likely it is recommended that the sub-base material is stabilized with cement or lime to provide support that is strongly resistant to erosion [9].

The other essential difference between the two types of pavements, flexible and rigid, is the manner in which they 


\section{International Journal of Engineering Applied Sciences and Technology, 2019 \\ Vol. 4, Issue 6, ISSN No. 2455-2143, Pages 20-28 \\ Published Online October 2019 in IJEAST (http://www.ijeast.com)}

distribute the load over the sub grade. Rigid pavement, because of concrete's rigidity and stiffness, tends to distribute the load over a relatively wide area of sub grade. The concrete slab itself supplies a major portion of a rigid pavement's structural capacity. Flexible pavement, inherently built with weaker and less stiff material, does not spread loads as well as concrete. Therefore, flexible pavements usually require more layers and greater thickness for optimally transmitting load to the sub grade.

Rigid pavements have the following advantages:

- It is feasible to design rigid pavements for very long design lives, up to 60 years and deterioration is usually very slow.

- Little maintenance is generally required.

- Rigid pavements do not deform under traffic.

- A relatively thin pavement slab distributes the load over a wide area due to its high rigidity.

- Concrete is very resistant to abrasion making the antiskidding surface texture last longer.

In the absence of deleterious materials (either in the aggregate or entering the concrete in solution from an external source) and unlike flexible pavements, concrete does not suffer significant deterioration from weathering. Neither its strength nor its stiffness is significantly affected by temperature changes.

\subsection{Comparison in terms of cost analysis}

Highway agencies are currently grappling with the identification and implementation of cost-effective practices to preserve the huge investment made in the highway infrastructure. Such practices are possible when agencies have built up a knowledge base of the costs and benefits of various interventions geared towards facility preservation. Such a knowledge base can assist the agency to select the best type of intervention under a given set of pavements, climatic and traffic loading conditions.

The biggest factors in variations in costs per lane kilometer are:

- Structures and interchanges: Projects that have structures and interchanges have a much higher cost per lane kilometer.

- Right of way: If a project can be built within existing right of way, then its cost per lane kilometer is much less than a project that needs additional right of way.

- Environmental impacts: Mitigation costs for environmental impacts have a dramatic effect on cost per lane kilometer.

- Existing soil and site conditions: Differing soil and site conditions also have an impact on the cost per lane kilometer.

The structural capacity of flexible pavements is attained by combined action of the different layers of the Pavement. The load is directly applied on the wearing course and it gets dispersed with depth in the base, sub-base and sub-grade layers and then ultimately to the ground. Since the stress induced by traffic load is highest at the top, the quality of top and upper layer materials is better. The sub-grade layer is responsible for transferring the load from above layers to the ground. Flexible pavements are designed in such a way that the load transmitted to the sub-grade does not exceed its bearing capacity. Consequently, the thickness of layers would vary with CBR of soil and it would affect the cost of the pavement.

\subsubsection{Initial cost estimation}

Initial cost is generally the major factor in deciding the type of the pavement in design. The planners often think that the flexible pavement is cheaper than the rigid pavements. In fact, this is not always the case. In the last decade the price of bitumen which is the main ingredient of flexible pavement has increased because of the increase in crude oil prices. However, the rigid pavement's main ingredient cement price is declining especially in Ethiopia. Countries like Ethiopia which import crude oil is directly affect by increasing crude oil price.

Government executives frequently have to choose between concrete and asphalt paving materials for roads and highways. In the last few years in asphalt which caused a dramatic escalation in asphalt prices reflected in a $250 \%$ increase during 2005-2008. It is likely that once the economic recovery gains traction, large shortages may reappear, oil prices will rise and asphalt prices will resume their upward climb. From 2003 to 2008 oil prices increased nearly 300\%. During the same period, liquid asphalt increased $250 \%$. The increases in asphalt prices during this period were not only a result of rising oil prices, but also by changes in oil refining practices which has led to a reduction in heavy crude production and reduced supply [3].

According to [3], "Initial Cost Comparison of Rigid and Flexible Pavements: Under Different Traffic and Soil Conditions", Longer term world economic growth is expected to be characterized by developing and transitional economies adding new demand pressures on oil prices. Longer term projections made by the United States government suggest that oil prices may exceed $\$ 180$ per barrel by 2030 .

Initial cost is the cost of construction of pavement which mainly depends up on the pavement thickness, governed by the strength of sub grade soil and traffic loading, cost of materials and cost of execution of the work. It has a wide range across the country and difficult to generalize.

Early cost estimates are critical factors to the initial decisionmaking process for capital projects. From the perspective of the infrastructure providers, accurate cost estimations allow for the effective budgeting and financing of a project. As such, the importance of early estimates to owners cannot be overemphasized. Early estimates are typically plagued by limited scope definition (and thus high potential for scope changes) and are often prepared under stiff time constraints. Furthermore, reliable cost data are frequently under attack to obtain during the conceptual stages of a project, particularly where basic route design and geographic site conditions of a road remain unresolved. Early estimates, even when grossly inaccurate, often become the basis upon which all future estimates are judged. 


\section{International Journal of Engineering Applied Sciences and Technology, 2019 \\ Vol. 4, Issue 6, ISSN No. 2455-2143, Pages 20-28 \\ Published Online October 2019 in IJEAST (http://www.ijeast.com)}

It is observed that flexible pavements are more economical for lesser volume of traffic. The life of flexible pavement is near about 15 years whose initial cost is low needs a periodic maintenance after a certain period and maintenance costs very high. The life of rigid pavement is much more than the flexible pavement of about 40 years approximately 2.5 times life of flexible pavement whose initial cost is much more than the flexible pavement but maintenance cost is very less.

\subsubsection{Life cycle cost}

When selecting a pavement alternative, it is important to understand the expected pavement performance and costs for the entire life-cycle of the pavement. The overall costs and value need to be determined over many years to effectively consider the different options in terms of pavement type, design life, and future rehabilitation. Life-cycle cost analysis (LCCA) has been used for many years to assist in making decisions regarding pavement type as well as selecting pavement preservation options.

Pavement service life is defined as the time between initial construction and the time when the pavement reaches a minimum acceptable service level. Actual service life with required rehabilitation treatment depends on a variety of factors. These can include the traffic/wheel loads, timeliness of maintenance treatments, and environmental factors such as temperature and precipitation. In order to develop comparative cost estimates over the pavement life, the timing, type and quantities of repairs and the corresponding activity service life must be known or estimated with reasonable accuracy.

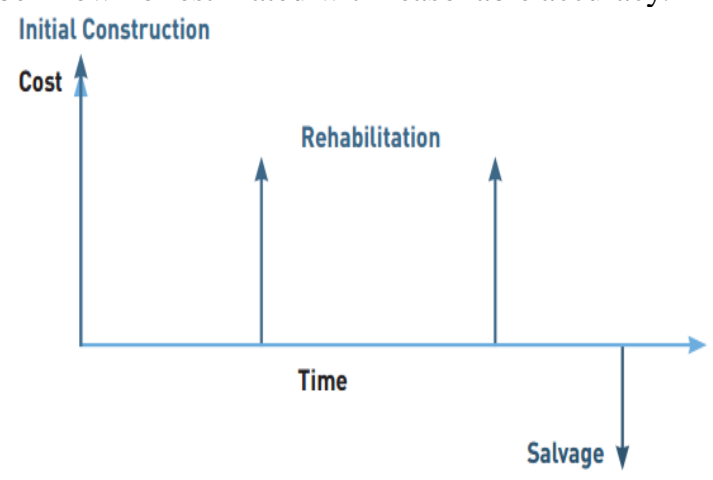

Figure-2: Life cycle cost Analysis(APA,2011)

In a typical LCCA, two or more alternate choices are available for an initial pavement design or cross-section. Based on the initial pavement designs, the expected maintenance and rehabilitation over the design life are then determined and incorporated into a single, inflation adjusted, cost in order to evaluate and to compare the different options in a fair and consistent manner.

For the maintenance and rehabilitation of concrete pavements, the most common activities include improving joint performance through resealing, partial depth repairs, and slab replacements with full depth repairs. On higher volume roadways, the smoothness of the roadway has more significance and some surface texturization is recommended to ensure an acceptable performance.

Hot mix asphalt pavements (flexible pavements) have been commonly used by Ethiopian government due to their history of use and experience with maintenance and rehabilitation. HMA pavements typically deteriorate faster than PCC (rigid pavement) pavements and require a more extensive maintenance schedule to maintain an acceptable level of service.

When evaluating the life-cycle cost, it is typically understood that there is a margin of error due to possible differences in quantities, unit costs, and pavement performance over the service life. Comparisons with marginal differences in cost may require further investigation into other factors to determine the optimal pavement type.

An increase in life-cycle cost for flexible pavements as traffic levels increase, particularly with low strength sub grade soils. This trend is typically because with increasing traffic loads, the thickness of the granular base/sub base and asphalt concrete layers required to support the traffic are proportionally higher than the increase in concrete thickness required. The decision to use life-cycle cost analysis and evaluate sustainable benefits including non-economic factors as part of the pavement type selection process provides government agencies with better knowledge of the true cost of a roadway rather than just considering the initial cost of the pavement.

\subsubsection{Maintenance cost}

Maintenance costs include costs for routine, preventive, and corrective maintenance, such as joint and crack sealing, void underselling, chip seal, patching, spall repair, individual slab replacements, thin HMA overlay etc. whose purpose is to preserve or extend the service life of a pavement.

Maintenance costs are frequently difficult to define because of either a lack of record keeping or accounting that does not appropriately discriminate between different types of maintenance activities. Maintenance costs in a life-cycle cost analysis usually have impact when compared to the initial and first rehabilitation costs. If maintenance costs are used within an LCCA procedure, then historical documentation of actual pavement activities and expenditures should be used. As with rehabilitation, unrealistically frequent or inappropriate maintenance activities can artificially increase LCC [7].

\section{SELECTION OF PAVEMENT TYPE}

Many designers tend to adopt flexible pavement in new design, partly because of the perceived difficultly in repairs of rigid pavement in busy areas. However, this approach is not necessarily cost effective, in particular when the oil price is on a far steeper rising trend in comparison with cement. Depending on the category of roads, maintenance difficulty of rigid pavement may not be an insurmountable factor either taking in to account the state of the art of technology [11]. 


\section{International Journal of Engineering Applied Sciences and Technology, 2019 \\ Vol. 4, Issue 6, ISSN No. 2455-2143, Pages 20-28 \\ Published Online October 2019 in IJEAST (http://www.ijeast.com)}

\subsection{Design of Rigid Pavement}

Rigid pavement consists of concrete slab and sub-base on top of the subgrade. Modulus of elasticity of concrete slab is normally much greater than that of granular sub-base and insitu subgrade, resulting in most of the load bearing capacity of a pavement being attributed to the strength of the concrete slab. Stresses in rigid pavements are induced by traffic loads and cyclic temperature changes of concrete slab, with their magnitudes also depending on the in-situ subgrade support. According to [11] for design purposes, longitudinally and transversely jointed concrete modelled as a system of hinged connected slabs on an elastic foundation that comprises the subgrade and the overlying sub-base. The elastic foundation is simulated by a series of springs of constant stiffness, which are characterized by the modulus of subgrade reaction. Only one slab is considered in the structural design, and the adjacent slabs are modelled to allow reduction of the imposed load along the edge the slab.

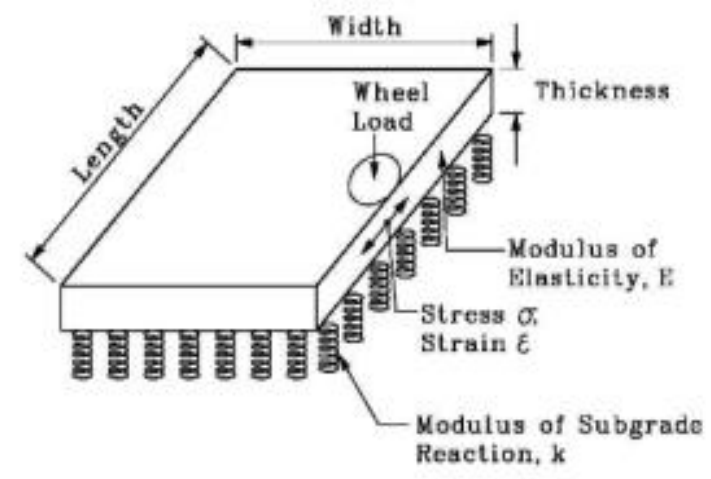

Figure-3: Model of Portland cement concrete

\subsubsection{Conformance design criteria's}

Generally, in design of Rigid (PCC) pavement three design criteria are essential: -

\section{I-Traffic Induced stresses}

Bending of a concrete slab due to traffic loading will generate both compressive and tensile stresses within the slab. In general, the thickness of the slab will be governed by maximum tensile stress within the slab. The critical loading point is along the slab edges in both longitudinal and transverse directions. The stresses are reduced by providing tie bar and dowel bar in both directions.

\section{II-Thermal stresses}

Thermal stresses consist of two components that are longitudinal stresses over the cross-section of the concrete due to seasonal temperature variations and warping stresses. Longitudinal tensile stresses -develop when the concrete cools and its contraction is prevented by the friction between the concrete slabs and sub-base. Stresses are greatest in the center of the slab and increase with slab longer.
Warping stresses- are the result of an uneven temperature distribution over the cross-section of the slab. If the top surface of a slab is warmer than the bottom surface, the slab becomes convex but its own gravity opposes such stress-free distortion, resulting in compressive stresses at the top and tensile stresses at the bottom of the slab.

\section{III-Fatigue stresses}

Concrete is subject to the effects of fatigue which are induced by repeated traffic loading and temperature variations. The fatigue behavior of concrete depends on the stress ratio which is the quotient of tensile stress and modulus of rupture of concrete.

\subsubsection{Design Life}

To achieve a design of low life cycle cost and in respect of the high social cost for full depth reconstruction, the design life for rigid pavement is generally recommended as $\mathbf{4 0}$ years. Within this life span, it is expected that no extensive rehabilitation is required under normal circumstances and the service life of the pavement structure can be sustained by minor repairs.

\subsubsection{Traffic Load}

The non-linear load transfer mechanism and the nonlinear fatigue damage occurring in rigid pavements hinder the practicality of expressing traffic load in term of equivalent standard axles. The damage induced by different loading conditions and magnitudes are separately analyzed by referring to a standard axle load distribution which was derived from sampled axle load data to represent the local traffic characteristic.

In order to have design traffic load a number of factors are influence load mechanism. These factors are: -

-Motorized Vehicle counting and forecasting

-Determination of equivalent axle per vehicles

-Distribution of Motorized vehicles per lane

-Determination of Design Traffic load

\subsubsection{Modulus of Sub grade Reaction}

In the design analysis, it is assumed that the reactive pressure provided by the sub-base or subgrade material under a concrete slab is proportional to the deformation below the point of loading. The ratio is known as the modulus of subgrade reaction 'or k-value. The value of the modulus of sub grade reaction taken based on [11].

Table-1; Modulus of sub-grade reaction $(\mathrm{Mpa} / \mathrm{mm})$

\begin{tabular}{|c|c|c|c|}
\hline \multirow{2}{*}{$\begin{array}{c}\text { E-subgrade } \\
(\mathrm{MPa})\end{array}$} & \multicolumn{3}{|c|}{ Thickness of Granular Sub-base } \\
\cline { 2 - 4 } & $150 \mathrm{~mm}$ & $225 \mathrm{~mm}$ & $300 \mathrm{~mm}$ \\
\hline 50 & 0.045 & 0.05 & 0.06 \\
\hline 100 & 0.06 & 0.075 & 0.09 \\
\hline 150 & 0.075 & 0.09 & 0.11 \\
\hline
\end{tabular}


International Journal of Engineering Applied Sciences and Technology, 2019

Vol. 4, Issue 6, ISSN No. 2455-2143, Pages 20-28

Published Online October 2019 in IJEAST (http://www.ijeast.com)

\begin{tabular}{|c|c|c|c|}
200 & 0.085 & 0.105 & 0.125 \\
\hline 250 & 0.095 & 0.115 & 0.14 \\
\hline 300 & 0.1 & 0.125 & 0.15 \\
\hline
\end{tabular}

\subsubsection{Portland Cement Concrete property}

Mostly, grade 40/20 concrete is specified for the construction of rigid pavements. The property of material is adopted in this pavement analysis based on [11]. The modulus rupture (5.25Mpa), modulus of elasticity (33Gpa), poisons ratio $(0.15)$ are used for design typical rigid pavement. For structural design of PCC pavement design charts are compulsory. Design charts also used for determination of slab thickness depend of up on the equivalent standard axle load (ESAL) and modulus sub-grade reaction [11].

Firstly, this design charts for slab length of $4 \mathrm{~m}$ are described below in Figure-4.

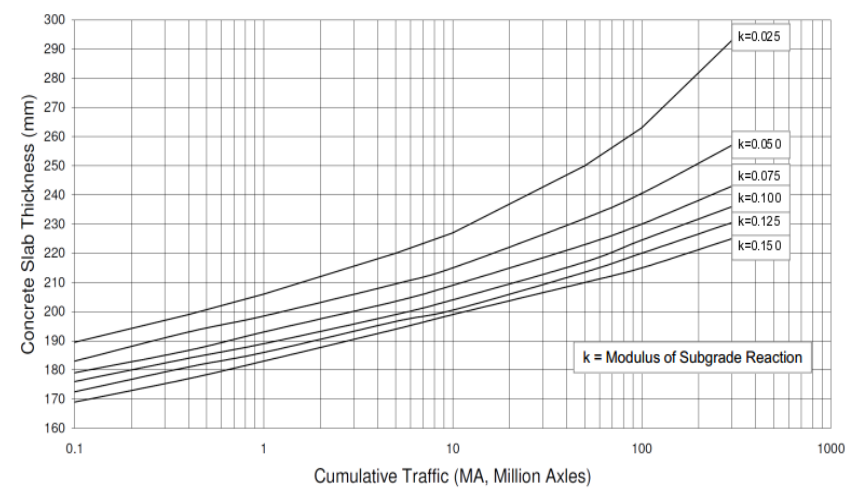

Figure-4: Design charts for slab thickness for length of $4 \mathrm{~m}$

Secondly, the design charts for slab length of $5 \mathrm{~m}$ is labelled in Figure-5 below

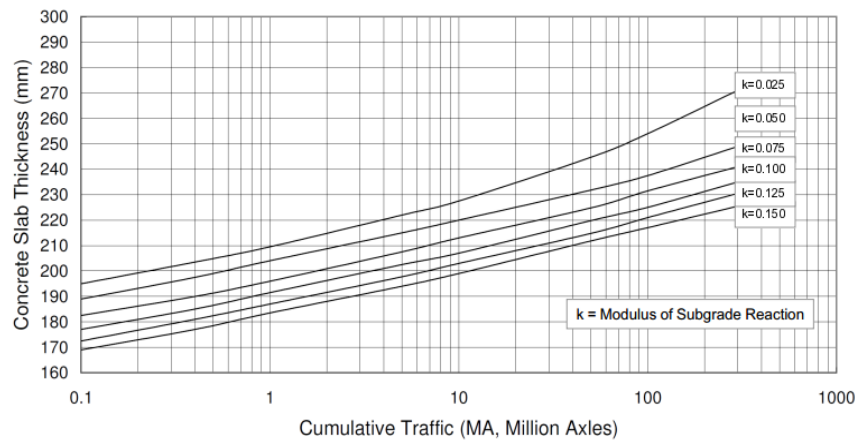

Figure-5: Design charts for slab thickness for length of $5 \mathrm{~m}$

Thirdly, this design charts for slab length of more than $6 \mathrm{~m}$ is displayed below Figure-6.

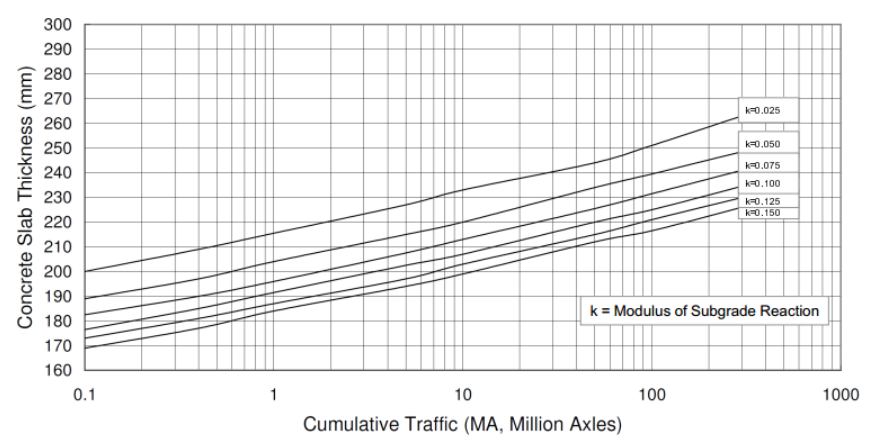

Figure-6: Design charts for slab thickness for length more than $6 \mathrm{~m}$

\subsubsection{Reinforcement Requirement}

Mostly for unreinforced concrete pavement when their slab length not more than $5 \mathrm{~m}$, their thermal and shrinkage effects within the concrete slabs can be released at saw-cut contraction joints timely provided in the construction, so that transverse cracking could be developed at the designed locations with no particular need of crack control using mesh reinforcement. To ensure proper load transfer across the contraction joints, dowel bars have to be mounted between them.

For reinforced concrete pavement when slab length longer than $5 \mathrm{~m}$, mesh reinforcement shall be provided in accordance with the requirements given in Table-2 to assist the distribution of traffic and thermal stresses [11].

Table-2; Minimum requirement of reinforcement

\begin{tabular}{|c|c|c|c|}
\hline \multirow{2}{*}{$\begin{array}{c}\text { Concrete } \\
\text { Slab } \\
\text { Thickness } \\
(\mathrm{mm})\end{array}$} & \multirow{2}{*}{$\begin{array}{c}\text { Mesh } \\
\left(\mathrm{kg} / \mathrm{m}^{2}\right)\end{array}$} & \multicolumn{2}{|c|}{ Cross section } \\
\hline & & $\begin{array}{c}\text { Main } \\
\left(\mathrm{mm}^{2} / \mathrm{m}\right)\end{array}$ & $\begin{array}{c}\text { Cross } \\
\left(\mathrm{mm}^{2} / \mathrm{m}\right)\end{array}$ \\
\hline$<170$ & 2.61 & 283 & 49 \\
\hline $170-210$ & 3.41 & 385 & 49 \\
\hline $210-235$ & 4.34 & 503 & 49 \\
\hline $235-300$ & 5.55 & 636 & 70.8 \\
\hline
\end{tabular}

\subsubsection{Joint Construction and Panel Design}

All reinforcement, dowels and tie bars shall be clean and free of oil, grease, loose rust and other foreign material when the concrete is placed. Paint free portions of dowels, including ends, with two coats of bituminous emulsion. The unpainted portions of dowels shall be installed in the initially placed concrete slab [2].

Construction of joint and proper paneling design in concrete slabs are vital to the sustainability and serviceability of rigid pavements. Unlike the continuous nature of flexible pavement, sufficient discontinuities are purposely provided between the concrete slabs to allow thermal movements. The physical 


\section{International Journal of Engineering Applied Sciences and Technology, 2019 \\ Vol. 4, Issue 6, ISSN No. 2455-2143, Pages 20-28 \\ Published Online October 2019 in IJEAST (http://www.ijeast.com)}

width of concrete slab is normally designed to match the traffic lane width, and separated by longitudinal joints to prevent longitudinal cracking. Along the traffic directions, suitable spacing and types of transverse joints shall be provided for thermal contraction and expansion and for isolation among the roads at their intersections.

\section{CONCLUSIONS}

For Rigid pavement construction the initial cost takes large portion from the total budget. Initial cost is the cost of construction of pavement which mainly depends up on the pavement thickness, governed by the strength of sub grade soil and traffic loading, cost of materials and cost of execution of the work. It has a wide range across the country and difficult to generalize. For the maintenance and rehabilitation of concrete pavements, the most common activities include improving joint performance through resealing, partial depth repairs, and slab replacements with full depth repairs. On higher volume roadways, the smoothness of the roadway has more significance and some surface texturization is recommended to ensure an acceptable performance.

These Rigid pavements are becoming selective and optimal pavement type in road construction, mostly in area of heavy load. In case of, Ethiopia the coverage of rigid pavement compare to the flexible pavement is not more than $1 \%$ due to various factors like unavailability of technology, lack of knowledge on advantage of this pavement and its initial cost but there are many sections and areas that need construction of this pavement due to load and duration (design period) requirements. The Ethiopian road authority and stakeholders have to give priority and focus for design and implementation of this pavement.

Mainly, hot mix asphalt pavements (flexible pavements) have been commonly used by Ethiopian government due to their history of use and experience with maintenance and rehabilitation. Hot mix asphalt (HMA) pavements typically deteriorate faster than PCC (rigid pavement) pavements and require a more extensive maintenance schedule to maintain an acceptable level of service.

The cost of bitumen increases from time to time and its production affects the environment, but when we see cement production its damage to the environment is lesser and its cost also much lower than bitumen, therefore using rigid pavement will increase sustainability. In this paper both flexible and rigid pavements are compared in various corner, in terms of cost (initial, life-cycle and maintenance) are described in detail about rigid and flexible pavements. Generally, starting from design criteria to panel design considerations are important to design proper section of rigid pavement, climatic condition and designers have to follow this approach for successful and effective design of rigid pavement. Therefore, by considering all necessarily point in design it is possible to adopt widely in our country Ethiopia.

\section{REFERENCE}

(1). Bhuyan, M. A. (2009). Evaluation Of Flexible And Rigid Pavements Construction in Bangladesh:MSc Thesis, Bangladesh: Bangladesh University.

(2). AACRA. (2003). Design and Construction Standards Technical Specifications on Concrete Pavement. Addis Ababa: Addis Ababa Road Authority.

(3). Akakin, T., Engin, Y. and Ucar, S. (1983). Initial Cost Comparison of Rigid and Flexible Pavements: Under Different Trafic And Soil Conditions, Turkey,(pg. 669-688).

(4). Alliance, A.P. (2010). Pavement type selection IM-4, Asphalt Pavement Alliance. Lanham, MD.

(5). APCA. (2002).Pavement type selection, American Pavement Concrete Association. USA.

(6). Alliance, A.P.(2010). Asphalt pavement: America rides on US, Asphalt Pavement Alliance,Lanham, MD.

(7). Alliance, A.P.(2011). Life-cycle cost analysis: A position paper.,Lanham, MD.

(8). ERA. (2002). Pavement Design Manual, Ethiopian Road Authority, Addis Ababa.

(9). ERA. (2013). Pavement Design Manual. Ethiopian Road Authority, Addis Ababa

(10). Bezabih, A.G and Chandra, S. (2009). Comparative study of flexiable and Rigid pavements for Different soil and traffic conditions, Journal of the Indian Roads Congress, (pg. 153-162).

(11). HDHK. (2013). Guidance Notes on Pavement Design For Carriageway Construction, Highway Departement of Hong Kong, Hong Kong.

(12). Jamal, H. (2017). Flexible Pavement Definition and Explanation. about civil.com.

(13). Mohod, M. V. and Kadam, K. N. (2016). A Comparative Study on Rigid and Flexible Pavement. Journal of Mechanical and Civil Engineering,Volume 13, pg. 85.

(14). Rogers, M. (2003). Highway Engineering. Dublin: Blackwell Publishing Ltd.

(15). Uijarevic, M. and Supic, S. (2016). Comparative Analysis Of Flexible And Rigid Pavement Design. Contemprary Achievements in Civil Engineering 22, Serbia, (pg. 591-601). 